\title{
PERSEPSI PETANI PADI SAWAH TERHADAP POLA KEMITRAAN DENGAN BADAN USAHA MILIK RAKYAT (BUMR) PANGAN
}

\section{PERCEPTION OF RICE FARMERS ON THE PARTNERSHIP PATTERN WITH SOCIETY-OWNED ENTERPRISES FOOD}

\author{
Riantin Hikmah Widi ${ }^{1}$, Tuti Karyani ${ }^{2}$, Hepi Hapsari ${ }^{2}$, \\ Lucyana Trimo ${ }^{2}$, Tedi Hartoyo ${ }^{1}$ \\ ${ }^{1}$ Fakultas Pertanian Universitas Siliwangi, Jl. Siliwangi No. 24 Tasikmalaya 46182 \\ ${ }^{2}$ Fakultas Pertanian, Universitas Padjadjaran, Jl. Raya Bandung - Sumedang Km 21 Hegarmanah \\ Kecamatan Jatinangor, Sumedang 45363 \\ *E-mail: riantinhikmahwidi@yahoo.co.id \\ (Diterima 13-02-2020; Disetujui 20-04-2020)
}

\begin{abstract}
ABSTRAK
Badan Usaha Milik Rakyat (BUMR) Pangan menawarkan pola kemitraan dengan petani guna mengatasi permasalahan-permasalahan klasik yang dihadapi petani selama ini, yaitu rendahnya permodalan, akses terhadap sumber permodalan, akses terhadap teknologi, dan penetrasi pasar. Pola kemitraan yang ditawarkan BUMR Pangan berupa bantuan pinjaman non kolateral yang disertai dengan pendampingan dan memberikan asuransi pertanian kepada petani. Petani diwajibkan menanam padi menggunakan varietas yang ditentukan oleh BUMR Pangan dan menjual gabahnya kepada BUMR Pangan dengan harga yang ditentukan berdasarkan kualitas gabah yang dihasilkan petani. Keputusan petani untuk menjalin kemitraan dengan BUMR Pangan sangat dipengaruhi oleh persepsinya terhadap pola kemitraan tersebut. Tujuan penelitian ini adalah untuk: (1) mengidentifikasi pola kemitraan petani padi sawah dengan BUMR Pangan, dan (2) menganalisis persepsi petani padi sawah terhadap pola kemitraan dengan BUMR Pangan. Metode penelitian yang digunakan adalah survey, dengan populasi seluruh petani padi sawah yang mengikuti pola kerjasama dengan BUMR Pangan di Kabupaten Sukabumi. Teknik pengambilan sampel yang digunakan adalah Simple Random Sampling. Tujuan penelitian pertama dianalisis secara deskriptif, sedangkan tujuan penelitian kedua dianalisis dengan menggunakan uji korelasi Rank Spearman. Hasil penelitian menunjukkan: (1) Pola kemitraan berupa Kerjasama Operasional Agribisnis (KOA), dimana perusahaan mitra (BUMR Pangan) memberikan pinjaman non kolateral, memberikan pendampingan teknik budidaya, dan bertindak sebagai offtaker (menerima hasil produksi), dan (2) Persepsi petani padi sawah terhadap pola kemitraan dengan BUMR Pangan pada umumnya positif, baik ditinjau dari aspek keuntungan relatif, tingkat kesesuaian serta tingkat kerumitan.
\end{abstract}

Kata kunci: Pola kemitraan, Persepsi, BUMR Pangan

ABSTRACT
Society-owned enterprises (BUMR) Food offer partnership patterns with farmers to overcome the
classic problems faced by farmers so far, namely the low capital, access to sources of capital,
access to technology, and market penetration. The partnership pattern offered by BUMR Food is in
the form of non-collateral loan assistance accompanied by assistance and providing agricultural
insurance to farmers. Farmers are required to plant rice using varieties determined by the BUMR
Food and sell their grain to BUMR Food at a price determined based on the quality of grain
produced by farmers. Farmers' decision to establish a partnership with BUMR Food is greatly
influenced by their perception of the partnership pattern. The purpose of this study is to: (1)
identify the pattern of partnership of paddy rice farmers with BUMR Food, and (2) analyze the
perception of paddy rice farmers to the pattern of partnership with BUMR Food. The research
method used was a survey, with a population of all paddy rice farmers who followed the pattern of 
collaboration with the BUMR Food in Sukabumi Regency. The sampling technique used is Simple Random Sampling. The first research objective was analyzed descriptively, while the second research objective was analyzed using the Spearman Rank correlation test. The results show: (1) The partnership pattern in the form of Agribusiness Operational Cooperation, where the partner company (BUMR Food) provides non-collateral loans, provides technical assistance in cultivation, and acts as an offtaker (receives the results of production), and (2) the perception of farmers lowland rice to the partnership pattern with BUMR Food is generally positive both in terms of relative profitability, suitability and complexity.

Keywords: artnership pattern, perception, BUMR Food

\section{PENDAHULUAN}

Kebanyakan petani di Indonesia adalah petani gurem dengan kepemilikan lahan di bawah 0,3 hektar (Direktorat Pembiayaan Pertanian Kementerian Pertanian, 2015). Karakteristik usahatani di Indonesia adalah kepemilikan lahan yang sempit, pemodalan yang terbatas, skala usaha terbatas, tingkat pendidikan rendah sehingga penguasaan atas teknologi rata-rata masih bersifat konvensional, risiko kegagalan panen yang tinggi akibat ketergantungan pada alam yang masih tinggi, serta lemahnya daya tawar dan penetrasi pasar. Kesemuanya ini saling terkait yang berujung pada rendahnya pendapatan yang diperoleh petani.

Salah satu upaya untuk mengatasi berbagai permasalahan terkait dengan karakteristik usahatani tersebut adalah dengan menjalin kemitraan. Salah satu lembaga yang mengadakan kemitraan dengan petani padi sawah di Sukabumi adalah BUMR Pangan. Pola kerjasama yang ditawarkan BUMR Pangan ini adalah selain memberikan bantuan dana berupa pinjaman non kolateral, juga memberikan pendampingan pelaksanaan teknik budidaya disertai dengan pengunaan teknologi canggih yang diberi nama I-Pangan. Selain itu, BUMR Pangan juga menawarkan asuransi bagi usahatani yang dilaksanakan petani. Manfaat yang diperoleh BUMR Pangan adalah terjaminnya stok gabah bagi usaha penggilingan padi yang dimilikinya, karena pembayaran pinjaman dilakukan secara yarnen, artinya petani membayar pinjamannya pada saat panen dalam bentuk gabah kering panen (GKP).

$$
\text { Menurut Dewi dkk (2011), }
$$
kemitraan merupakan pilihan terbaik bagi petani untuk meningkatkan pendapatannya karena melalui kemitraan tersebut petani mendapatkan jaminan harga dan pasar dari mitranya. Keputusan petani untuk mengikuti kemitraan tergantung pada faktor-faktor yang mempengaruhinya. 
Ponnusamy (2013) menyatakan bahwa pola kerjasama di bidang pertanian dapat mengatasi keterbatasan di bidang pertanian seperti pengadaan input, sumber daya, penerasi pasar, resiko kegagalan panen yang tinggi serta penguasaan teknologi yang masih rendah.

Hasil penelitian Prasetyo (2014) dalam Falah dkk (2018) menunjukan bahwa mayoritas persepsi petani adalah cukup baik, petani beranggapan bahwa jalannya kemitraan selama ini sudah berjalan baik. Petani merasa sudah menerima manfaat dari kemitraan yang mereka jalani seperti peningkatan pendapatan, pengetahuan dan kualitas hasil panen sayuran mereka.

Penelitian ini dilaksanakan dengan tujuan untuk: (1) mengidentifikasi pola kemitraan petani padi sawah dengan BUMR Pangan, dan (2) menganalisis persepsi petani padi sawah terhadap pola kemitraan dengan BUMR Pangan.

\section{METODE PENELITIAN}

Penelitian dilaksanakan dengan menggunakan metode survey pada petani padi sawah di Kabupaten Sukabumi yang ditentukan secara sengaja sebagai lokasi penelitian dengan pertimbangan banyaknya petani padi sawah yang mengikuti pola kemitraan dengan BUMR Pangan.

Populasi petani padi sawah yang mengikuti kemitraan dengan BUMR Pangan sebanyak 540, dan sampel diambil $1 \%$ dari populasi sehingga jumlah sampel penelitian sebanyak 54 orang.

Persepsi petani padi sawah terhadap pola kemitraan dengan BUMR Pangan dianalisis dengan menggunakan Skala Likert (Tabel 1). Variabel yang diukur dalam skala Likert dijabarkan menjadi indikator variabel yang dijadikan sebagai titik tolak untuk menyusun item-item instrumen yang dapat berupa pernyataan atau pertanyaan (Sugiyono, 2016).

Persepsi petani padi sawah terhadap pola kemitraan dengan BUMR Pangan diukur dengan menggunakan Skala Likert dengan skor 1 (tidak setuju), skor 2 (ragu-ragu), dan skor 3 (setuju); kemudian data tersebut dianalisis dengan menghitung:

a. Skor maksimal yaitu skor jawaban terbesar dikali banyaknya item/indikator.

b. Skor minimum yaitu skor jawaban terkecil dikali banyaknya item/indikator. 
c. Nilai median (Me), yaitu hasil penjumlahan skor maksimum dengan skor minimum dibagi 2.

d. Nilai kuartil ke satu (K1), yaitu hasil penjumlahan skor minimum dengan nilai median dibagi 2 .

e. Nilai kuartil ke tiga (K3), yaitu hasil penjumlahan skor maksimum dengan median dibagi 2.
Berdasarkan perhitungan tersebut, maka persepsi petani padi sawah terhadap pola kemitraan dengan BUMR Pangan dikategorikan sebagai berikut:

a. Sangat positif : $\mathrm{K} 3 \leq \mathrm{X} \leq$ skor maks

b. Positif : $\mathrm{Me} \leq \mathrm{X}<\mathrm{K} 3$

c. Negatif : $\mathrm{K} 1 \leq \mathrm{X}<\mathrm{Me}$

d. Sangat negatif : Skor $\min \leq \mathrm{X}<\mathrm{K} 1$

\section{Tabel 1. Variabel Penelitian}

\begin{tabular}{|c|c|c|c|c|}
\hline Variabel & Indikator & Item & $\begin{array}{l}\text { Skala } \\
\text { Ukur }\end{array}$ & Skor \\
\hline \multirow{13}{*}{$\begin{array}{l}\text { Persepsi Petani } \\
\text { terhadap } \\
\text { Program } \\
\text { kemitraan } \\
\text { dengan BUMR } \\
\text { Pangan }\end{array}$} & \multirow[t]{5}{*}{$\begin{array}{l}\text { Keuntungan } \\
\text { relatif }\end{array}$} & $\begin{array}{l}\text { 1. Petani mendapatkan pendampingan teknik } \\
\text { budidaya secara lebih intensif. }\end{array}$ & Ordinal & $1-3$ \\
\hline & & $\begin{array}{l}\text { 2. Petani mendapatkan kemudahan dalam } \\
\text { mengakses input produksi }\end{array}$ & Ordinal & $1-3$ \\
\hline & & $\begin{array}{l}\text { 3. Petani mendapatkan kemudahan dalam } \\
\text { mengakses pembiayaan kepada pihak } \\
\text { perbankan }\end{array}$ & Ordinal & $1-3$ \\
\hline & & $\begin{array}{l}\text { 4. Petani mendapatkan proteksi asuransi } \\
\text { pertanian }\end{array}$ & Ordinal & $1-3$ \\
\hline & & $\begin{array}{l}\text { 5. Petani mendapatkan jaminan pemasaran } \\
\text { produk dan harga jual yang lebih tinggi. }\end{array}$ & Ordinal & $1-3$ \\
\hline & \multirow[t]{4}{*}{ Kesesuaian } & $\begin{array}{l}\text { 1. Terdapat kesesuaian antara materi } \\
\text { pendampingan budidaya yang diberikan } \\
\text { dengan kebutuhan petani. }\end{array}$ & Ordinal & $1-3$ \\
\hline & & $\begin{array}{l}\text { 2. Terdapat kesesuaian antara ketersediaan dan } \\
\text { kebutuhan input }\end{array}$ & Ordinal & $1-3$ \\
\hline & & $\begin{array}{l}\text { 3. Terdapat kesesuaian antara skim kredit yang } \\
\text { diberikan dengan kebutuhan petani }\end{array}$ & Ordinal & $1-3$ \\
\hline & & $\begin{array}{l}\text { 4. Terdapat kesesuaian antara harga produk yang } \\
\text { dbayar dengan harapan petani }\end{array}$ & Ordinal & $1-3$ \\
\hline & \multirow[t]{4}{*}{ Kerumitan } & $\begin{array}{l}\text { 1. Petani tidak menemukan kesulitan dalam } \\
\text { menerapkan teknik budidaya yang dianjurkan. }\end{array}$ & Ordinal & $1-3$ \\
\hline & & $\begin{array}{l}\text { 2. Petani mendapatkan kemudahan dalam } \\
\text { mengakses input produksi. } \\
\text { 3. Petani tidak menemukan kesulitan dalam }\end{array}$ & Ordinal & $1-3$ \\
\hline & & $\begin{array}{l}\text { proses pengajuan kredit program. } \\
\text { 4. Petani tidak menemukan kesulitan dalam }\end{array}$ & Ordinal & $1-3$ \\
\hline & & memasarkan hasil produksinya & Ordinal & $1-3$ \\
\hline
\end{tabular}

Sumber: Diadaptasi dari Utomo (2012) 
HASIL DAN PEMBAHASAN

\section{Pola Kemitraan Petani dengan BUMR} Pangan

Pola kemitraan adalah suatu bentuk hubungan yang saling menguntungkan dan saling melengkapi. Dalam menjalin kemitraan dengan petani padi sawah,
BUMR Pangan juga melibatkan koperasi Ar-Rohmah sebagai lembaga perantara yang mewadahi petani padi sawah, serta PT. Pertamina sebagai sumber keuangan melalui program Program Kemitraan Bina Lingkungan (PKBL) yang disajikan pada Gambar 1.

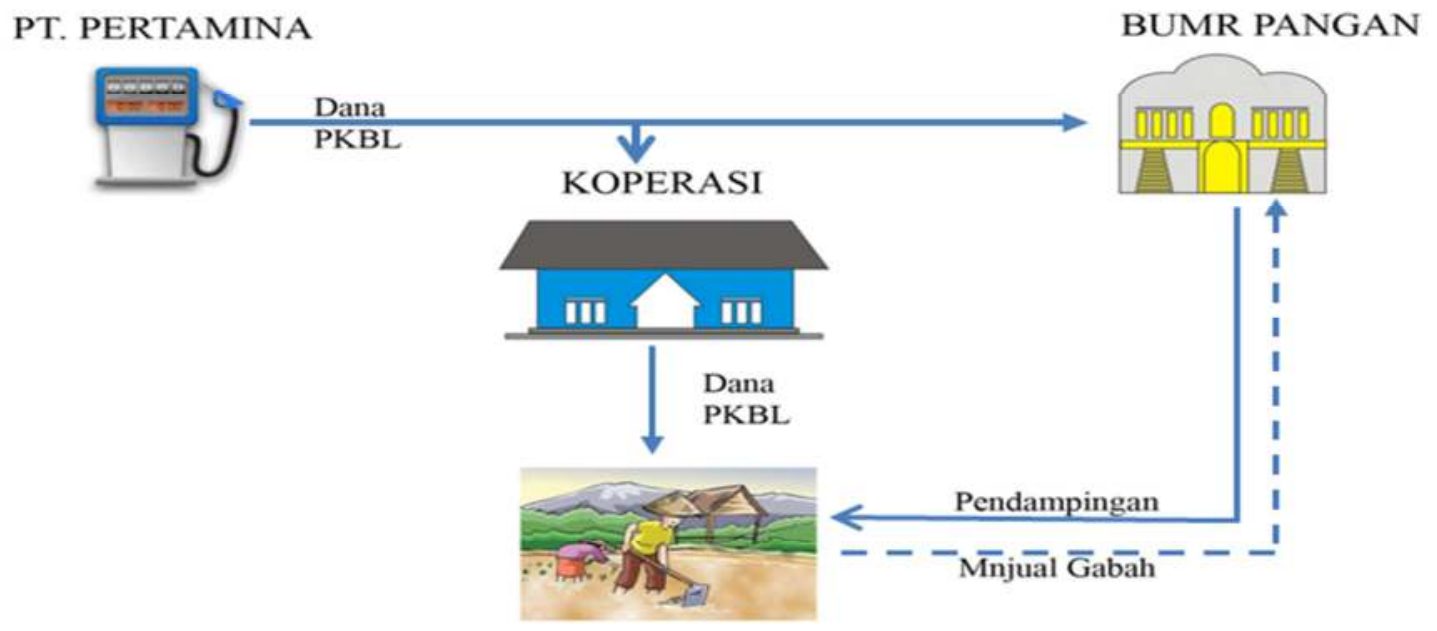

\section{Gambar 1. Lembaga yang Terlibat dalam Bisnis BUMR Pangan}

Gambar 1 menunjukkan empat stakeholder yang terlibat di dalam bisnis yang dijalankan oleh BUMR Pangan ini. Adapun tugas dan peran dari masingmasing stakeholder ini dapat dijabarkan sebagai berikut:

\section{a. PT. Pertamina}

Peran yang dijalankan PT. Pertamina adalah memberikan dana bantuan bergulir PKBL kepada BUMR Pangan. Dana bantuan ini bersumber dari dana CSR PT Pertamina. Dana ini harus dikembalikan kepada PT Pertamina setiap akhir musim tanam. Dana bantuan ini dikucurkan Pertamina kepada BUMR Pangan melalui Koperasi Ar-Rohmah. Dana bantuan diperuntukkan bagi petani padi sawah yang ada di sekitar lokasi BUMR Pangan. Dana bantuan baru digulirkan oleh PT Pertamina jika telah terpenuhinya 1.000 ha lahan pertanian.

\section{b. Koperasi}

Koperasi Ar-Rohmah dibentuk BUMR Pangan sebagai salah satu syarat pencairan dana bantuan PKBL dari Pertamina. Selain bertindak sebagai lembaga perantara pencairan dana PKBL, koperasi juga memiliki peran untuk 
merekrut anggota yaitu para petani padi sawah yang nanti akan menjadi sasaran pemberian dana pinjaman dari BUMR Pangan. Para petani padi sawah yang telah memenuhi syarat akan diberikan pinjaman yang pencairannya melibatkan Bank Syariah Mandiri. Dana akan cair setelah akad kredit berlangsung. Koperasi juga bertindak sebagai lembaga yang akan menampung hasil produksi para petani, yang selanjutnya akan diserahkan kepada BUMR Pangan.

\section{c. Petani}

Petani yang mendapatkan bantuan pinjaman adalah petani padi sawah, baik petani pemilik, penyewa maupun penggarap. Hal ini disebabkan karena tidak adanya persyaratan agunan bagi petani yang akan meminjam. Penilaian layak tidaknya petani hanya didasarkan pada penilaian yang dilakukan para pendamping (dari pihak BUMR Pangan) serta luasan lahan garapan yang dimiliki. Besarnya pinjaman yang diberikan sesuai kebutuhan masing-masing petani, namun besarnya plafon adalah Rp 13.460.000 per hektar lahan sawah yang digarap. Petani memiliki kewajiban untuk mengembalikan pinjamannya pada saat panen. Pembayaran dilakukan dengan menggunakan gabah kering pungut (GKP) atau gabah kering giling (GKG) dengan harga yang telah ditentukan oleh BUMR Pangan. Penentuan harga dilakukan sesuai dengan kualitas gabah yang dihasilkan. Petani disarankan untuk menanam padi dengan varietas Inpago Unsoed 1 karena varietas padi inilah yang akan diolah oleh BUMR Pangan di pabrik penggilingan padinya sebagai beras dengan kelas premium.

\section{d. BUMR Pangan}

Terdapat beberapa peran yang dijalankan BUMR Pangan. Pertama, BUMR Pangan bertindak sebagai manajemen pengelola keuangan. BUMR Pangan yang akan menentukan petani padi sawah yang boleh meminjam serta berapa besar kuota pinjaman bagi setiap petani. Guna memperoleh keakuratan, BUMR Pangan menggunakan drone untuk melakukan pemetaan lahan petani sehingga diperoleh berapa luasan lahan garapan yang dimiliki petani serta bagaimana tingkat kesuburan tanahnya. Hingga pada akhirnya dapat diprediksikan tingkat produktivitas serta hasil panennya nanti. Hal ini yang digunakan sebagai dasar pertimbangan menentukan petani layak mendapat pinjaman atau tidak, selain adanya pertimbangan karakter yang dimiliki petani (hasil pengamatan pendamping). Kedua, BUMR melakukan pendamping- 
an secara teknik pada proses budidaya dengan menggunakan aplikasi I-Pangan untuk menentukan berapa dosis pupuk yang harus digunakan. Selain itu, aplikasi juga digunakan untuk menentukan jenis serangan hama dan penyakit serta dosis pestisida yang diperlukan. Diharapkan melalui proses pendampingan ini, petani dapat meningkatkan produktivitas usahataninya. Ketiga, BUMR Pangan mengatur pencairan kredit kepada petani. Pada umumnya pencairan kredit dilakukan melalui 3 (tiga) tahap. Tahap pertama adalah pada tahap persiapan lahan dimana dana yang dicairkan sebesar $30 \%$ dari jumlah pinjaman. Tahap kedua 30\% lagi dicairkan setelah memasuki tahap pemeliharaan, dan tahap ketiga sebanyak $40 \%$ dicairkan pada saat memasuki masa panen. Tujuan pencairan dana secara bertahap ini adalah agar dana pinjaman ini benar-benar digunakan petani untuk biaya usahataninya, bukan diperuntukkan bagi pembiayaan lainnya.

Jika dilihat dari pola kemitraan yang dijalani, maka pola kemitraan antara petani padi sawah dengan BUMR Pangan mengacu pada pola kemitraan Kerjasama Oprasiomal Agribisnis (KOA).

KOA Agribisnis adalah hubungan kemitraan antara kelompok mitra dengan pemisahaan mitra usaha yang di dalamnya kelompok mitra menyediakan lahan, sarana dan tenaga, sedangkan perusahaan mitra menyediakan biaya atau modal usaha dengan sarana untuk mengusahakan atau membudidayakan suatu komoditas pertanian (Harisman, 2017).

\section{Persepsi Petani Terhadap Pola Kemitraan dengan BUMR Pangan}

Pola kemitraan antara petani padi sawah dengan BUMR Pangan di Kabupaten Sukabumi didasari oleh kepentingan yang saling menguntungkan kedua belah pihak, yang dilaksanakan dalam jangka waktu tertentu dengan prinsip saling membesarkan dan saling membutuhkan sesuai dengan prinsip dari kemitraan itu sendiri. BUMR Pangan sebagai suatu lembaga yang memiliki pabrik penggilingan padi (rice milling) memerlukan kemitraan dengan petani padi sawah agar pasokan gabah sebagai bahan baku rice milling nya dapat tetap terjaga. Sementara petani padi sawah memerlukan kemitraan dengan BUMR Pangan agar petani dapat mengatasi permasalahan klasik yang sering dihadapi seperti keterbatasan modal, keterbatasan teknologi dan penetrasi pasar.

Namun demikian, kenyataan di lapangan seringkali terdapat hal-hal yang 
tidak sesuai dengan harapan kedua belah pihak. Penilaian petani terhadap pola kemitraan dengan BUMR Pangan sangat dipengaruhi oleh persepsinya. Dimana persepsi petani juga sangat dipengaruhi oleh karakteristik petani itu sendiri (Rakhmat, 2013).

Persepsi petani padi terhadap pola kemitraan dengan BUMR Pangan dapat didekati dengan tiga indikator (Rogers, 1983), yaitu keuntungan relatif (relative advantages), tingkat kesesuaian (compatibility) dan tingkat kerumitan (complexity).

\section{Persepsi Petani Padi Sawah terhadap Relative Advantages (Keuntungan Relatif) dari Pola Kemitraan dengan BUMR Pangan}

Keputusan petani untuk melakukan pola kemitraan dengan BUMR Pangan tentunya didasari oleh adanya persepsi tentang manfaat (keuntungan relatif) yang diperoleh petani (sebagai adaptor). Melalui pola kemitraan dengan BUMR Pangan, petani akan mendapatkan pendampingan teknik budidaya padi secara lebih intensif.
BUMR Pangan telah menggunakan teknologi 4.0 guna memantau tingkat kesuburan tanah milik petani, sehingga dapat ditentukan secara tepat berapa dosis pupuk yang harus digunakan. Selain itu, BUMR Pangan juga telah memanfaatkan aplikasi I-Pangan guna mendeteksi adanya serangan hama penyakit dan serangga serta penanggulangannya. Lebih jelasnya tentang aplikasi I-Pangan ini dapat dilihat pada Gambar 2.

Melalui Pola kemitraan dengan BUMR Pangan, petani juga dapat membeli pupuk dengan mudah, karena BUMR Pangan dapat mengkoordinir pembelian pupuk bagi petani. BUMR Pangan juga memfasilitasi pemberian pinjaman non kolateral kepada petani dengan dana pinjaman bersumber dari dana PKBL PT Pertamina. Pinjaman tersebut disertai dengan pemberian proteksi berupa asuransi pertanian. Lebih jelasnya mengenai persepsi petani padi sawah terhadap pola kemitraan dengan BUMR Pangan dari aspek keuntungan relatif dapat dilihat pada Tabel 2. 


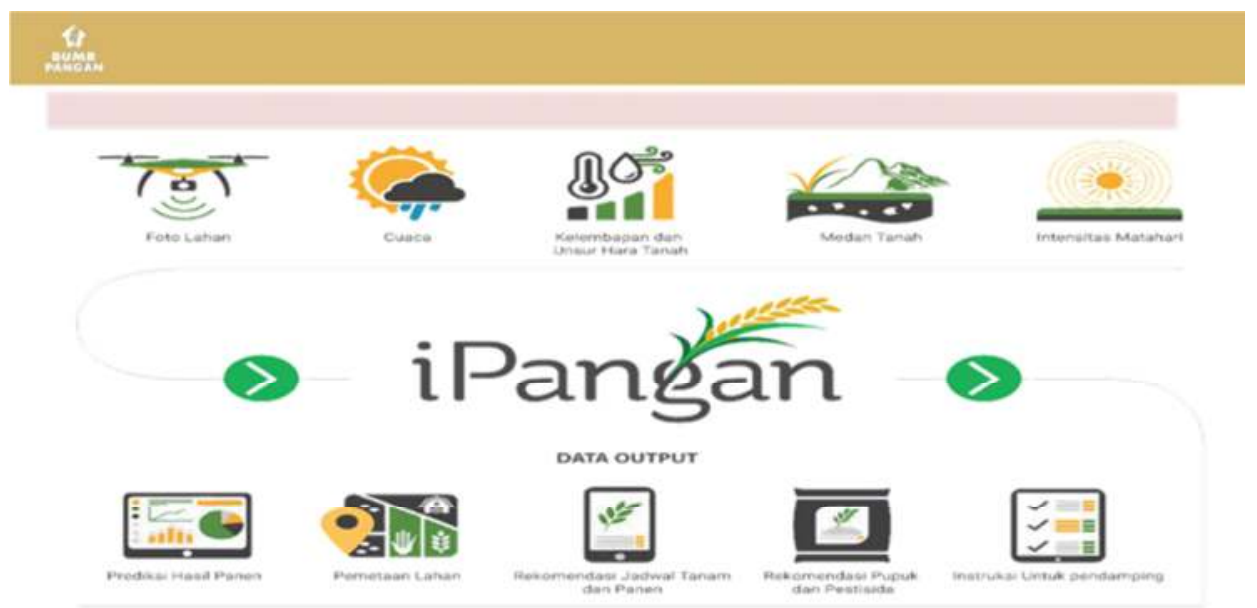

Gambar 2. Teknologi 4.0 (I-Pangan)

Tabel 2. Persepsi Petani terhadap Pola Kemitraan dengan BUMR Pangan Ditinjau dari Aspek Keuntungan Relatif

\begin{tabular}{lccc}
\hline \multicolumn{1}{c}{ Kategori Persepsi } & Kategori Skor & Jumlah Petani (orang) & Persentasi (\%) \\
\hline Sangat Positif & $12,5 \leq \mathrm{x}<15,0$ & 15 & 27,8 \\
Positif & $10,0 \leq \mathrm{x}<12,5$ & 35 & 66,7 \\
Negatif & $7,5 \leq \mathrm{x}<10,0$ & 3 & 5,5 \\
Sangat Negatif & $5,0 \leq \mathrm{x}<7,5$ & - & - \\
\hline
\end{tabular}

Sumber: Data Primer diolah, 2019

Pada Tabel 2 terlihat terdapat 35 orang atau $66,7 \%$ petani padi sawah memberikan persepsi yang positif terhadap pola kemitraan dengan BUMR Pangan, bahkan terdapat $27,8 \%$ petani responden memberikan persepsi yang sangat positif. Hal ini menunjukkan bahwa jalinan kerjasama dengan BUMR Pangan sangat diyakini oleh petani padi sawah di daerah Sukabumi akan memberikan keuntungan bagi petani terutama dalam mengatasi keterbatasan modal yang dimiliki petani melalui pemberian pinjaman non kolateral sehingga petani padi dapat meningkatkan taraf hidupnya. Hal ini sejalan dengan yang dikemukakan oleh Nwaru et al (2011) dan Saleem (2011), yang menyatakan bahwa kredit dan bantuan modal dapat meningkatkan taraf hidup petani miskin melalui perbaikan produksi dan peningkatan konsumsi. Hanya ada 3 orang petani atau 5,5\% yang memberikan persepsi negatif.

\section{Persepsi Petani Padi Sawah terhadap Pola Kemitraan dengan BUMR Pangan dipandang dari Tingkat Kesesuaian (Compatibility)}

Dilihat dari tingkat kesesuaiannya, terdapat 31 orang atau $57,4 \%$ petani 
responden yang memberikan persepsi positif terhadap pola kemitraan dengan BUMR Pangan. Mereka menganggap bahwa pinjaman non kolateral ini sangat meringankan beban petani, karena selama ini keterbatasan akses petani dengan sumber keuangan terkendala dengan ketiadaan agunan yang dimiliki petani (Usman, 2004). Petani responden juga menganggap besaran pinjaman yang diberikan sudah sesuai dengan kebutuhan. BUMR Pangan memberikan plafon kredit kepada petani sebesar $\mathrm{Rp}$ 13.460.000 per hektarnya yang dicairkan dalam tiga tahap. Angka ini masih lebih besar dari biaya usahatani padi per hektar yang diterbitkan Badan Pusat Statistik (2015) yaitu Rp 12.700.000.

Guna lebih jelasnya persepsi petani responden terhadap pola kemitraan dengan BUMR Pangan ditinjau dari tingkat kesesuaian dapat dilihat pada Tabel 3.

Tabel 3. Persepsi Petani Padi Sawah terhadap Pola Kemitraan dengan BUMR Pangan ditinjau dari Tingkat Kesesuaian (Capability)

\begin{tabular}{lccc}
\hline \multicolumn{1}{c}{ Kategori Persepsi } & Kategori Skor & Jumlah Petani (orang) & Persentasi (\%) \\
\hline Sangat Positif & $10,0 \leq \mathrm{x}<12,0$ & 21 & 38,9 \\
Positif & $8,0 \leq \mathrm{x}<10,0$ & 31 & 57,4 \\
Negatif & $6,0 \leq \mathrm{x}<8,0$ & 2 & 3,7 \\
Sangat Negatif & $4,0 \leq \mathrm{x}<6,0$ & - & - \\
\hline
\end{tabular}

Sumber: Data primer diolah, 2019

Persepsi Petani Padi Sawah Terhadap

Pola Kemitraan dengan BUMR Pangan Ditinjau dari Tingkat Kerumitan (Complexity)

Rogers (1983) mendefinisikan tingkat kerumitan (complexity) dalam mengukur persepsi sebagai suatu tingkat dimana suatu inovasi dianggap relatif sulit untuk dimengerti dan digunakan. Sekaitan dengan persepsi petani responden terhadap pola kemitraan dengan BUMR Pangan, indikator yang digunakan adalah bagaimana tingkat kerumitan penerapan teknik budidaya yang dianjurkan, bagaimana ketersediaan input produksi, bagaimana prosedur pengajuan kredit (pinjaman) serta bagaimana pemasaran hasil produk. Kategori persepsi petani responden untuk tingkat kerumitan ini dapat dilihat pada Tabel 4. 
Tabel 4. Persepsi Petani Padi Sawah Terhadap Pola Kemitraan Dengan BUMR Pangan ditinjau dari Tingkat Kerumitan (Complexity)

\begin{tabular}{lccc}
\hline \multicolumn{1}{c}{ Kategori Persepsi } & Kategori Skor & Jumlah Petani (orang) & Persentasi (\%) \\
\hline Sangat Positif & $10,0 \leq \mathrm{x}<12,0$ & 9 & 16,6 \\
Positif & $8,0 \leq \mathrm{x}<10,0$ & 32 & 59,3 \\
Negatif & $6,0 \leq \mathrm{x}<8,0$ & 13 & 24,1 \\
Sangat Negatif & $4,0 \leq \mathrm{x}<6,0$ & - & - \\
\hline & & 54 & 100,0 \\
\hline
\end{tabular}

Sumber: Data Primer diolah, 2019

Tabel 4 menunjukkan 59,3\% (32 orang) petani responden memiliki persepsi positif terhadap tingkat kerumitan dalam menjalin pola kemitraan dengan BUMR Pangan. Walaupun BUMR Pangan menerapkan konsep budidaya padi sawah sisem Pengelolaan Peranian Terpadu (PTT) dengan menggunakan teknologi 4.0 (I-Pangan), namun petani responden tidak menemui kesulitan berarti karena penggunaan teknologi maju tersebut lebih banyak dilakukan oleh pendamping, sedangkan petani hanya melakukan apa yang disarankan oleh pendamping. Dalam pengajuan kredit, petani juga tidak diminta persyaratan agunan, tetapi cukup menyerahkan data diri saja. Proses pencairan pun tidak memakan waktu yang lama. Petani yang memberikan persepsi negatif, lebih kepada petani yang menanam padi dengan varietas yang tidak sesuai dengan yang dianjurkan sehingga BUMR Pangan tidak bersedia membeli produk yang dihasilkan.
Varietas yang dianjurkan adalah varietas Inpago Unsoed 1, tetapi petani juga diberi kebebasan untuk menggunakan varietas yang lain, asal tampilan fisik gabahnya adalah panjang-panjang karena beras yang dipasarkan BUMR Pangan adalah kelas premium.

\section{KESIMPULAN DAN SARAN}

\section{Kesimpulan}

1. Pola kemiraan antara petani padi sawah dengan BUMR Pangan memiliki pola yang khas karena selain BUMR Pangan, ada lembaga lain yang ikut terlibat yaitu koperasi serta PT Pertamina. Namun demikian, cenderung mengarah pada pola kemitraan Kerjasama Operasional Agribisnis (KOA), dimana perusahaan mitra (BUMR Pangan) memberikan pinjaman non kolateral, memberikan pendampingan teknik budidaya dan bertindak sebagai offtaker (menerima hasil produksi).

2. Persepsi petani padi sawah terhadap pola kemitraan dengan BUMR 
Pangan pada umumnya positif, baik ditinjau dari aspek keuntungan relatif, tingkat kesesuain serta tingkat kerumitan.

\section{Saran}

1. Dalam membuat program kemitraan dengan petani padi sawah, hendaknya BUMR Pangan juga mempertimbangkan karakteristik petani agar program dapat berjalan sesuai target.

2. Walaupun persepsi petani terhadap kemitraan dengan BUMR Pangan berada pada kategori positif, namun BUMR Pangan harus tetap memperhatikan hal-hal yang menyebabkan beberapa petani masih memberikan persepsi negatif, seperti tetap menampung hasil produksi padi dari petani mitra walaupun tidak sesuai dengan kriteria, dengan memberikan harga yang sedikit lebih rendah.

\section{UCAPAN TERIMA KASIH}

Ucapan terima kasih kepada LP2MPMP Universitas Siliwangi yang telah memberikan dana hibah untuk penelitian ini melalui skema Penelitian Pengembangan Kapasitas Tahun Anggaran 2019/2020.

\section{DAFTAR PUSTAKA}

Badan Pusat Statistik, (2015). http://www.bps.go.id/statictable/20 15/09/25/1855/nilai-produksi-danbiaya-produksi-per-musim-tanamper-hektar-budidaya-tanaman-padisawah-padi-ladang-jagung-dankedelai-2014.html.

Dewi, B.P.K., Setiawan B. dan Isaskar, R. (2011). Analisis Kemitraan PT. Benih Citra Asia dengan Petani Tomat (Licopersium esculantum, Mill) (Studi Kasus di Desa Jambewangi, Kecamatan Sempu, Kabupaten Banyuwangi. Habitat XII(2): 98-117.

Falah, H.H., Sudarko dan Subekti, S. (2018). Persepsi Petani Cabai Besar dan Pengelola Koperasi Terhadap Kemitraan Agribisnis. Agriekonomika, 7(1) 2018: 72-84

Harisman, K. (2017). Pola Kemitraan Antara Petani dengan PT. Indofood Fryto-Lay Makmur Pada Usahatani Kentang Industri Varietas Atlantik (Suatu Kasus di Desa Cigedug Kecamatan Cigedug Kabupaten Garut). Jurnal ISTEK, X(1): 101116.

Nwaru, J.C., Essien, U.A. and Onuoha, R.E. (2011). Determinants of Informal Credit Demand and Supply among Food Crop Farmers in Akwa Ibom State, Nigeria. Journal of Rural and Community Development, 6(1): 129-139.

Ponnusamy, K. (2013). Impact of public private partnership in agriculture: A review. Indian Journal of Agricultural Science, 83(8): 803808.

Rahmat, J. (2000). Psikologi Komunikasi. Bandung: Remaja Rosdakarya.

Rogers, E.M. (1983). Diffusion of Innovasions, Third Edition. New York: The Free Press.

Saleem, M.A. and Jan, F.A. (2011). The Impact of Agricultural Credit on 
Agricultural Productivity in Dera Ismail Khan (District) Khyber Pakhtonkhawa Pakistan. European Journal of Business and Management, 3(2): 38-44.

Sugiyono. 2016. Metode Penelitian Kuantitatif, Kualitatif, dan $R \& D$. Bandung: Alfabeta.
Utomo, P. (2012). Persepsi Petani Terhadap Metode Budidaya Padi System of Rice Intensification (SRI) di Desa Ringgit Kecamatan Ngombol Kabupaten Purworejo. Skripsi. Universitas Muhammadiyah Purworejo. 